\title{
Relationship Between Serum Total Testosterone Concentration and Augmentation Index at Radial Artery in Japanese Postmenopausal Patients
}

\author{
Takashi Hitsumoto
}

\begin{abstract}
Background: The significance of testosterone as a risk factor for cardiovascular disease (CVD) in females is controversial. This cross-sectional study aimed to elucidate the relationship between serum total testosterone concentration (T-T) and augmentation index at the radial artery (r-AIx) as a marker of arterial function in Japanese postmenopausal patients.
\end{abstract}

Methods: A total of 447 postmenopausal patients with traditional cardiovascular risk factors and/or a history of CVD (age (mean \pm standard deviation (SD)), $73 \pm 10$ years) were enrolled. r-AIx was measured using tonometry, and the association between r-AIx and various clinical parameters, including T-T, was determined.

Results: r-AIx significantly increased (CVD vs. non-CVD: $99 \pm 11 \%$ vs. $91 \pm 11 \%, \mathrm{P}<0.001)$ and T-T significantly decreased (CVD vs. non-CVD: $0.31 \pm 0.13 \mathrm{ng} / \mathrm{mL}$ vs. $0.49 \pm 0.23 \mathrm{ng} / \mathrm{mL}, \mathrm{P}<0.001)$ in patients with CVD than in those without CVD. A significant negative correlation $(\mathrm{r}=-0.48 ; \mathrm{P}<0.001)$ between $\mathrm{r}-\mathrm{AIx}$ and $\mathrm{T}-\mathrm{T}$ was observed. Furthermore, multiple regression analysis indicated that T-T ( $\mathrm{t}$ value $=-7.7 ; \mathrm{P}<0.001)$, height $(\mathrm{t}$ value $=-5.3 ; \mathrm{P}<0.001), \mathrm{d}-\mathrm{ROMs}$ test as a marker of oxidative stress in vivo $(\mathrm{t}$ value $=3.2 ; \mathrm{P}<0.001)$, $\mathrm{CVD}(\mathrm{t}$ value $=2.9 ; \mathrm{P}<0.01)$, and pulse rate $(\mathrm{t}$ value $=-2.7 ; \mathrm{P}<0.01)$ were independent variables for $\mathrm{r}-\mathrm{AIx}$ as a subordinate factor.

Conclusion: This study revealed that low T-T is an important determining factor for an increase in r-AIx in Japanese postmenopausal patients. A prospective multicenter study with a large sample size is required to confirm the results of this study.

Keywords: Testosterone; Augmentation index; Oxidative stress; Cardiovascular disease; Female

\section{Introduction}

Testosterone is an important sex hormone that influences

Manuscript submitted August 12, 2017, accepted August 25, 2017

Hitsumoto Medical Clinic, 2-7-7, Takezakicyou, Shimonoseki City, Yamaguchi 750-0025, Japan. Email: thitsu@jcom.home.ne.jp

doi: https://doi.org/10.14740/jocmr3164w various health problems in males. In particular, recent clinical studies indicated that low blood testosterone concentration in males is closely associated with the incidence of cardiovascular disease (CVD) [1]. Testosterone is also produced in females but at levels approximately $5-10 \%$ of the levels in males. Recent studies have indicated that testosterone is also associated with female health. The significance of blood testosterone concentration as a risk factor for CVD in females is controversial. Several clinical studies have indicated that high blood testosterone concentration in females is associated with the incidence of CVD [2, 3]. However, Sievers et al reported that low serum total testosterone concentration (T-T) in German female patients was associated with a higher incidence of CVD events compared with high T-T [4]. Such reports mainly involve analysis of the Caucasian population.

Augmentation index (AIx) is known to indicate arterial wave reflection [5]. Clinical studies have reported that elevated AIx and central blood pressure are important predictors of CVD [6-9]. However, few studies have reported the association between AIx and blood testosterone concentration in females $[10,11]$. To the best of our knowledge, there are no studies reporting the association between AIx and blood testosterone concentration in the Asian female population. This study aimed to elucidate the association between T-T and AIx at radial artery (r-AIx) in Japanese postmenopausal patients.

\section{Materials and Methods}

\section{Patients}

This cross-sectional study was performed at the Hitsumoto Medical Clinic in Yamaguchi, Japan, between September 2014 and August 2016. T-T, r-AIx, and various clinical parameters were analyzed in 447 postmenopausal patients with traditional cardiovascular risk factors and/or a history of CVD (age (mean \pm standard deviation (SD)), $73 \pm 10$ years). Patients administered dehydroepiandrosterone, estradiol, and testosterone were excluded from the study. Clinical history of CVD was defined as previous ischemic heart disease, cerebrovascular disease, peripheral arterial disease, or heart failure according to medical records. All patients provided informed consent, and the study protocol was approved by the local ethics committee of the Hitsumoto Medical Clinic. 


\section{Measurement of r-AIx}

r-AIx was measured in a temperature-controlled room maintained between 20 and $25{ }^{\circ} \mathrm{C}$. Patients undergoing treatment with antihypertensive drugs ceased treatment more than $24 \mathrm{~h}$ before measurement. r-AIx of the patient was measured in the sitting position using an applanation tonometry-based device (HEM-9010AI, Omron Healthcare Co., Ltd, Kyoto, Japan), as previously described $[4,12]$. The tonometry sensor is a pressure sensor composed of an array of 40 microtransducer elements. On placing the sensor on a patient's wrist, one of the microtransducers is automatically selected to obtain optimal radial pressure waveforms. The first and second systolic peaks are automatically detected and consequently r-AIx is measured. The validity and reliability of r-AIx measurement by this method are well established; several studies have indicated a close linear correlation between r-AIx and central AIx [5, 9, $12]$.

\section{Evaluation of cardiovascular risk factors}

Obesity was assessed using body mass index, which was calculated as the ratio of weight $(\mathrm{kg})$ to square of height $(\mathrm{m})$. A current smoker was defined as an individual who smoked at least one cigarette per day during the previous 28 days. Right brachial blood pressure was measured twice using a mercury sphygmomanometer with patients in the sitting position. An average of two readings was used to determine systolic and diastolic blood pressures. Hypertension was defined as systolic blood pressure $\geq 140 \mathrm{~mm} \mathrm{Hg}$ and/or diastolic blood pressure $\geq 90 \mathrm{~mm} \mathrm{Hg}$ and/or under antihypertensive treatment. Dyslipidemia was defined as a serum low-density lipoprotein cholesterol concentration $\geq 140 \mathrm{mg} / \mathrm{dL}$, a serum high-density lipoprotein cholesterol concentration $\leq 40 \mathrm{mg} / \mathrm{dL}$, and/or a serum triglyceride concentration $\geq 150 \mathrm{mg} / \mathrm{dL}$ and/or under antihyperlipidemic treatment. Diabetes mellitus was defined as fasting blood glucose level $\geq 126 \mathrm{mg} / \mathrm{dL}$ and/or under antidiabetic treatment.

\section{Blood sampling}

Blood samples were collected from the antecubital vein in the morning after $12 \mathrm{~h}$ of fasting. Serum lipid concentration, plasma glucose concentration, serum insulin concentration, serum high-sensitivity C-reactive protein (hs-CRP) concentration, reactive oxygen metabolites (d-ROMs) test as a marker of oxidative stress, serum estradiol concentration, and T-T were subsequently measured. Total cholesterol and triglyceride concentrations were measured by standard enzymatic methods. High-density lipoprotein cholesterol concentration was measured by selective inhibition. Low-density lipoprotein cholesterol concentration was calculated using the Friedewald formula [13]. Patients with a serum triglyceride concentration $\geq 400 \mathrm{mg} / \mathrm{dL}$ were excluded because the method is accurate only below this concentration. Plasma glucose concentration was measured by the glucose oxidase method, and serum in-
Table 1. Patient Characteristics

\begin{tabular}{|c|c|}
\hline $\mathrm{n}$ & 447 \\
\hline Age (years) & $73 \pm 10$ \\
\hline Height (m) & $1.57 \pm 0.09$ \\
\hline Body weight (kg) & $56 \pm 10$ \\
\hline Body mass index $\left(\mathrm{kg} / \mathrm{m}^{2}\right)$ & $22.8 \pm 3.8$ \\
\hline Current smoker (\%) & $32(7)$ \\
\hline Hypertension (\%) & $321(72)$ \\
\hline Systolic BP (mm Hg) & $146 \pm 8$ \\
\hline Diastolic BP (mm Hg) & $89 \pm 9$ \\
\hline Pulse rate (/min) & $68 \pm 18$ \\
\hline Dyslipidemia (\%) & $268(60)$ \\
\hline Diabetes mellitus (\%) & $139(31)$ \\
\hline CVD (\%) & $143(32)$ \\
\hline Total cholesterol (mg/dL) & $214 \pm 38$ \\
\hline LDL-cholesterol (mg/dL) & $134 \pm 35$ \\
\hline Triglyceride (mg/dL) & $132 \pm 56$ \\
\hline HDL-cholesterol (mg/dL) & $53 \pm 14$ \\
\hline FBG (mg/dL) & $112 \pm 24$ \\
\hline IRI $(\mu \mathrm{g} / \mathrm{mL})$ & $7.3 \pm 4.6$ \\
\hline HOMA-IR & $2.0 \pm 1.4$ \\
\hline Log hs-CRP (mg/L) & $-1.3 \pm 0.6$ \\
\hline d-ROMs test (U. Carr) & $309 \pm 82$ \\
\hline Detection of estradiol (\%) & $377(84)$ \\
\hline Estradiol (pg/mL) & $7.8 \pm 3.3$ \\
\hline $\mathrm{T}-\mathrm{T}(\mathrm{ng} / \mathrm{mL})$ & $0.4 \pm 0.2$ \\
\hline r-AIx(\%) & $94 \pm 12$ \\
\hline \multicolumn{2}{|l|}{ Medications } \\
\hline RAS inhibitor (\%) & $197(44)$ \\
\hline Statin $(\%)$ & $160(36)$ \\
\hline
\end{tabular}

Data are expressed mean \pm SD. BP: blood pressure; CVD: cardiovascular disease; LDL: low-density lipoprotein; HDL: high-density lipoprotein; FBG: fasting blood glucose; IRI: immunoreactive insulin; HOMAIR: homeostatic model assessment of insulin resistance; hs-CRP: high-sensitivity C-reactive protein; d-ROMs: derivatives of reactive oxygen metabolites; T-T: total testosterone; r-Alx: radial augmentation index; RAS: renin- angiotensin system.

sulin concentration was measured by enzyme immunoassay. To measure insulin resistance, the homeostatic model assessment of insulin resistance (HOMA-IR) was used as follows [14]: HOMA-IR = fasting glucose concentration $(\mathrm{mg} / \mathrm{dL}) \times$ fasting immunoreactive insulin concentration $(\mu \mathrm{g} / \mathrm{mL}) / 405$. hs-CRP concentration was measured using high-sensitivity, latex-enhanced immunonephelometrics. The d-ROMs test, which reflects blood hydroperoxide concentrations, was performed using a commercial kit (Diacron, Grosseto, Italy) [15]. Serum estradiol concentration was measured using a commercial kit (ARCHITECT Estradiol II, Chicago, IL, USA). Detection limit of estradiol using this kit is $5 \mathrm{pg} / \mathrm{mL}$. T-T was also 

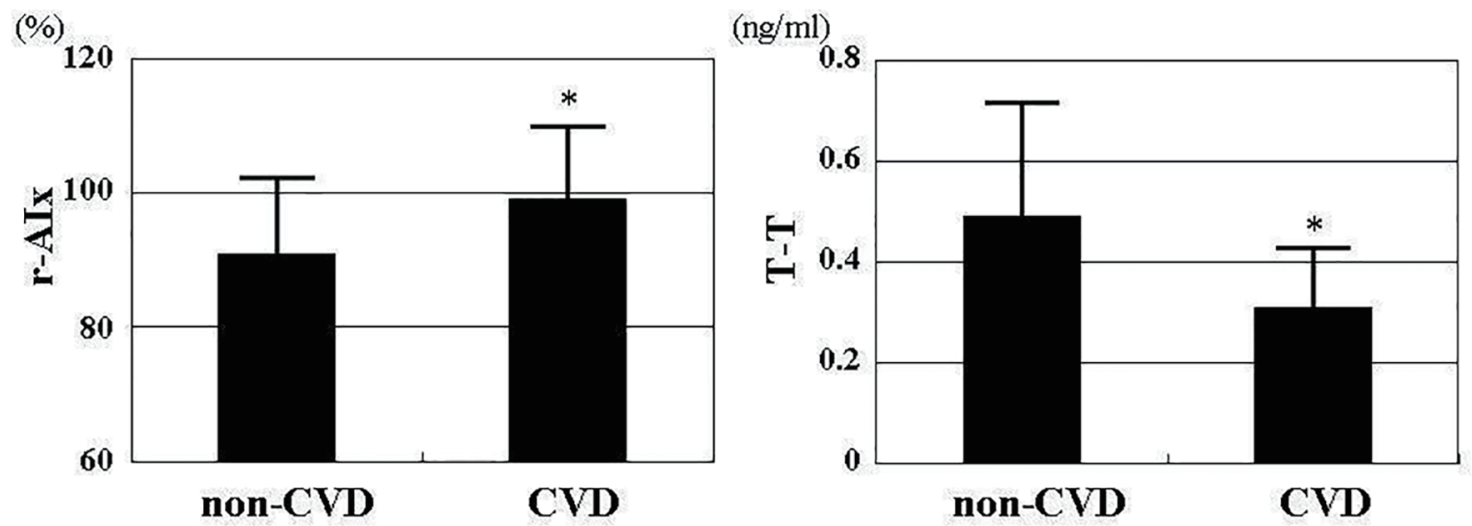

Figure 1. Comparisons of r-Alx or T-T between non-CVD and CVD patients. r-Alx significantly increased (CVD vs. non-CVD: $99 \pm 11 \%$ vs. $91 \pm 11 \%, P<0.001$ ) and T-T significantly decreased (CVD vs. non-CVD: $0.31 \pm 0.13 \mathrm{ng} / \mathrm{mL}$ vs. $0.49 \pm 0.23 \mathrm{ng} / \mathrm{mL}, P$ $<0.001$ ) in CVD patients than in non-CVD patients. r-Alx: radial augmentation index; T-T: serum total testosterone concentration; CVD: cardiovascular disease. ${ }^{*} \mathrm{P}<0.001$ vs. non-CVD.

measured using a commercial kit (ARCHITECT Testosterone II, Chicago, IL, USA).

\section{Statistical analysis}

A commercially available statistical software program (StatView-J 5.0, Hulinks, Inc., Tokyo, Japan) was used for all statistical analyses. Continuous variables were expressed as the mean \pm SD. Between-group comparisons were performed using the Student's $t$-test. The correlation coefficient was estimated by Spearman's rank correlation analysis. Multivariate analysis was performed using multiple regression analysis. A P value of $<0.05$ was considered statistically significant.

\section{Results}

Baseline clinical characteristics are shown in Table 1. The mean value of r-AIx was $94 \pm 12 \%$ (range, $60-134 \%$ ), and the mean value of T-T was $0.43 \pm 0.22 \mathrm{ng} / \mathrm{mL}$ (range, $0.06-1.55 \mathrm{ng} /$ $\mathrm{mL}$ ). These parameters indicated a nearly normal distribution. Comparisons of r-AIx or T-T between non-CVD and CVD patients are shown in Figure 1. r-AIx significantly increased and $\mathrm{T}-\mathrm{T}$ significantly decreased in CVD patients than in non-CVD patients. The association between r-AIx and T-T is shown in Figure 2. A significant negative correlation between r-AIx and $\mathrm{T}$-T was observed. The association between r-AIx or T-T and various clinical parameters is shown in Table 2. r-AIx showed a significant positive correlation with age, current smoking, hypertension, systolic blood pressure, hs-CRP concentration, and d-ROMs. Conversely, r-AIx showed a significant negative correlation with height, pulse rate, and serum estradiol concentration. T-T showed a significant positive correlation with hypertension, serum estradiol concentration. Conversely, T-T showed a significant negative correlation with age, diabetes mellitus, plasma glucose concentration, serum insulin concentration, HOMA-IR, hs-CRP concentration, and d-ROMs.

For further analysis of the independent association be- tween r-AIx and T-T, multiple regression analysis was performed to evaluate the ability of 15 factors, including T-T, to explain r-AIx as a subordinate factor. Coefficient of determination $\left(\mathrm{R}^{2}\right)$ of this analysis is 0.32 , indicating that $32 \%$ of r-AIx as a subordinate factor is explained by 15 explanatory factors. Variance ratio ( $\mathrm{F}$ value) of this analysis is 25.9 , and significance level is statistically significant $(\mathrm{P}<0.001)$. In this analysis, five factors (T-T, height, d-ROMs test, history of CVD, and pulse rate) were selected as independent variables for r-AIx (Table 3).

\section{Discussion}

The significance of AIx in females as a risk factor for CVD is controversial. Janner et al reported that AIx is a predictor for CVD endpoint in males but not in females [16]. However, other researchers indicated the importance of AIx as a risk factor for CVD in females. Higashi et al reported that increase in carotid AIx reflected the impairment of left ventricular diastolic function in females but not in males [17]. Yasmin et al reported that AIx had a significant positive correlation with pulse-wave velocity as a marker of arterial stiffness in males and females [18]. Furthermore, other clinical researches also indicated a significant correlation between biomarker of inflammation or vascular calcification and AIx in female patients $[19,20]$. These reports indicated that increase in AIx in female patients was associated with CVD. In the present crosssectional study, r-AIx significantly increased in CVD patients than in non-CVD patients; furthermore, multivariate analysis indicated that CVD was an independent variable for r-AIx as a subordinate factor. In contrast, the results of this study indicated that T-T significantly decreased in CVD patients than in non-CVD patients. Thus, results of the present study and the previous study supported the increase in AIx and decrease in blood testosterone concentration as considerable risk factors for CVD not only in the Caucasian population but also in the Asian female population.

Several mechanisms explaining the vasoprotective effects 


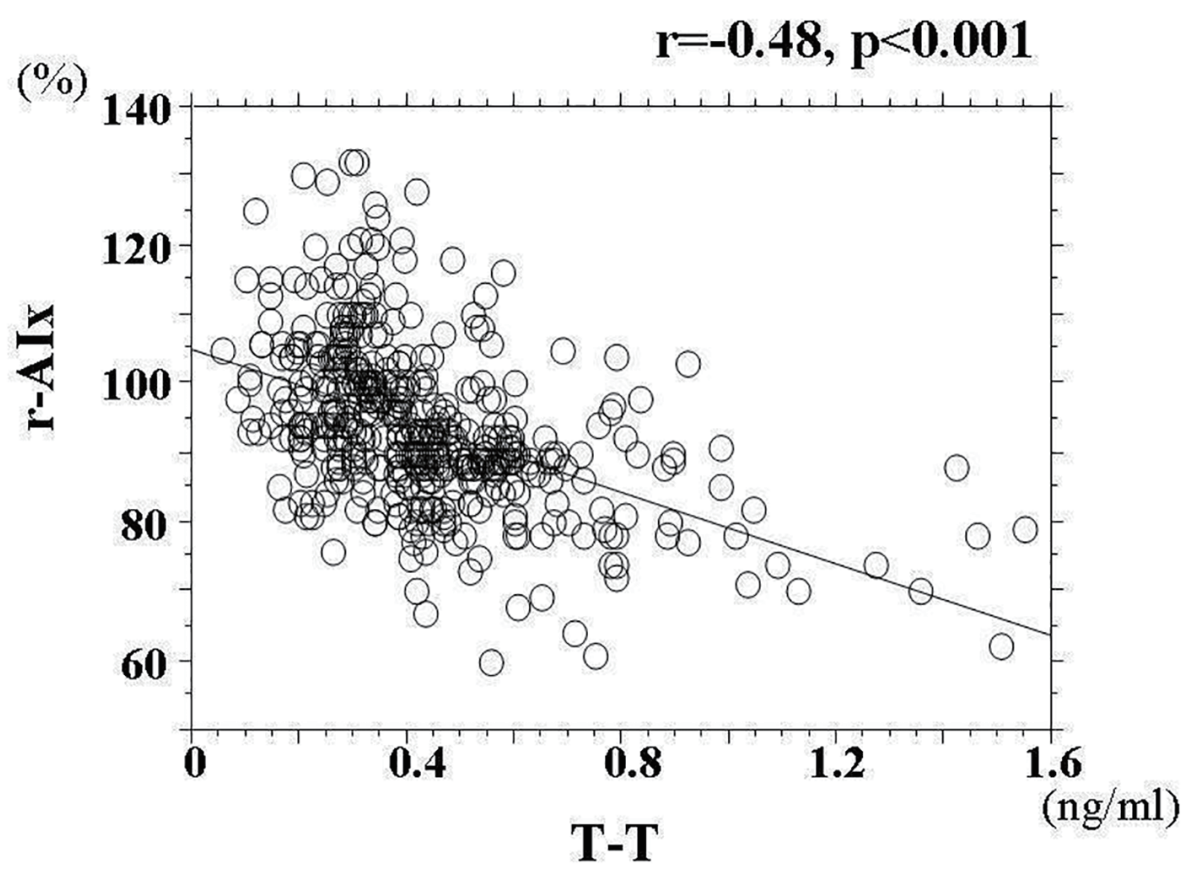

Figure 2. The association between r-Alx and T-T. A significant negative correlation between r-Alx and T-T $(r=-0.48, P<0.001)$ was observed. r-Alx: radial augmentation index; T-T: serum total testosterone concentration.

of testosterone such as vasodilatory effects, retention of endothelial function, and inhibition of vascular calcification have been reported $[21,22]$. Clinical studies have indicated a significant association between low blood testosterone concentration and the impairment of markers for arterial function such as pulse-wave velocity, flow-mediated dilatation, and AIx in males [23-25]. Weiss et al reported a significant decrease in AIx and increase in blood testosterone concentration by oral administration of dehydroepiandrosterone in older adults, of whom 96.7\% were Caucasian and 54.3\% were female [11]. Furthermore, the results of the present study indicated that low blood testosterone concentration is an important determining factor for increase in AIx in the Asian postmenopausal population. AIx is known to be influenced by arterial stiffness or endothelial function in addition to height and pulse rate [26, 27]. In contrast, clinical studies reported that low T-T had a significant negative correlation with cardio-ankle vascular index as a marker of arterial stiffness or administration of testosterone improved endothelial function in postmenopausal patients [28, 29]. Therefore, a significant association between low T-T and r-AIx in the present study may be partly attributed to increased arterial stiffness or endothelial dysfunction owing to low testosterone levels. Decrease of estrogen in postmenopausal patients is widely known to be associated with various health problems, including arterial dysfunction. In this study, serum estradiol concentration had a significant negative correlation with r-AIx in univariate analysis. However, multivariate analysis indicated that serum estradiol concentration was not an independent variable for r-AIx. Weiss et al also reported that there was no association between the decrease in AIx and increase in blood estradiol concentration by oral administration of dehydroepiandrosterone [11]. Therefore, the results of the present study and those of Weiss et al's study indicated that testosterone is a more important sex hormone than estrogen for AIx in postmenopausal patients.

A number of basic and clinical studies have illustrated that the increase in oxidative stress contributes to the development of atherosclerosis [30, 31]. Furthermore, some clinical studies have reported that there is a significant association between oxidative stress and AIx $[32,33]$. The results of the present study also indicated that d-ROMs test, as a marker of oxidative stress in vivo, is selected as an independent factor for r-AIx in postmenopausal patients. In contrast, low blood testosterone concentration is reported to be associated with oxidative stress in males [34]. The results of the present study also indicated a significant association between oxidative stress and testosterone in postmenopausal patients. The association between oxidative stress and testosterone is controversial. Some basic studies have indicated that testosterone suppresses oxidative stress $[35,36]$. In contrast, other studies reported that testosterone promotes oxidative stress [37-39]. Skogastierna et al reported that supraphysiological dose of testosterone induced oxidative stress in vitro and in vivo [40]. Therefore, the physiological levels of testosterone in postmenopausal patients in this study may have suppressed oxidative stress in vivo. Further studies concerning the association between oxidative stress and testosterone in postmenopausal patients, including intervention therapy such as the administration of dehydroepiandrosterone or testosterone, are warranted.

\section{Limitations}

There are several limitations of this study. First, patients un- 
Table 2. Relationships Between r-Alx, T-T and Various Clinical Parameters

\begin{tabular}{|c|c|c|}
\hline & \multicolumn{2}{|c|}{$\mathbf{r}$} \\
\hline & r-AIx & T-T \\
\hline Age & $0.22 *$ & $-0.28 *$ \\
\hline Height & $-0.29 *$ & -0.05 \\
\hline Body weight & -0.05 & -0.07 \\
\hline Body mass index & -0.09 & -0.07 \\
\hline Current smoker $($ yes $=1$, no $=0)$ & $0.15^{* *}$ & 0.04 \\
\hline Hypertension $($ yes $=1$, no $=0)$ & $0.13 * *$ & $0.13 * *$ \\
\hline Systolic BP & $0.11^{* * *}$ & 0.08 \\
\hline Diastolic BP & 0.07 & 0.06 \\
\hline Pulse rate & $-0.21 *$ & 0.08 \\
\hline Dyslipidemia $($ yes $=1$, no $=0$ ) & 0.03 & 0.02 \\
\hline Diabetes mellitus (yes $=1$, no $=0$ ) & 0.09 & $-0.16^{* *}$ \\
\hline Total cholesterol & 0.03 & -0.04 \\
\hline LDL-cholesterol & 0.02 & -0.03 \\
\hline Triglyceride & -0.04 & -0.03 \\
\hline HDL-cholesterol & 0.03 & 0.02 \\
\hline FBG & 0.09 & $-0.11 * * *$ \\
\hline IRI & 0.08 & $-0.12 * *$ \\
\hline HOMA-IR & 0.09 & $-0.12 * *$ \\
\hline Log hs-CRP & $0.21 *$ & $-0.28 *$ \\
\hline d-ROMs test & $0.40 *$ & $-0.41 *$ \\
\hline $\begin{array}{l}\text { Detection of estradiol } \\
(\text { yes }=1, \text { no }=0)\end{array}$ & $-0.21 *$ & $0.43^{*}$ \\
\hline Estradiol & $-0.13 * *$ & $0.24 *$ \\
\hline RAS inhibitor $($ yes $=1$, no $=0$ ) & -0.09 & -0.09 \\
\hline Statin $($ yes $=1$, no $=0)$ & -0.08 & -0.07 \\
\hline
\end{tabular}

r-Alx: radial augmentation index; T-T: total testosterone; BP: blood pressure; LDL: low-density lipoprotein; HDL: high-density lipoprotein; FBG: fasting blood glucose; IRI: immunoreactive insulin; HOMA-IR: homeostatic model assessment of insulin resistance; hs-CRP: highsensitivity C-reactive protein; d-ROMs: derivatives of reactive oxygen metabolites; RAS: renin-angiotensin system.

dergoing treatment with antihypertensive drugs ceased treatment more than $24 \mathrm{~h}$ before measurement of r-AIx to avoid the influence. However, $24 \mathrm{~h}$ was not sufficient to avoid the effect of long-acting drugs such as amlodipine. Second, angiography, computed tomography, and magnetic resonance imaging were not performed. Therefore, asymptomatic CVD may have been undetected. Third, this study was cross-sectional in a single unit, and the sample size was relatively small. A prospective multicenter study with a large sample size is necessary to confirm the significance of r-AIx or blood testosterone concentration as a risk factor for CVD in postmenopausal subjects. Furthermore, an extensive examination of basic and clinical studies investigating the significance of r-AIx or T-T as a risk factor for CVD in females is required in the future.
Table 3. Multiple Regression Analysis for $\mathrm{r}-\mathrm{Alx}$

\begin{tabular}{llll}
\hline Explanatory factor & $\boldsymbol{\beta}$ & t value & P value \\
\hline T-T & -0.38 & -7.7 & $<0.001$ \\
Height & -0.22 & -5.3 & $<0.001$ \\
d-ROMs test & 0.17 & 3.2 & $<0.001$ \\
CVD & 0.15 & 2.9 & $<0.01$ \\
Pulse rate & -0.14 & -2.7 & $<0.01$ \\
Age & 0.09 & 1.9 & 0.053 \\
Hypertension & 0.08 & 0.7 & 0.104 \\
FBG & 0.07 & 1.5 & 0.158 \\
Diabetes mellitus & 0.07 & 1.4 & 0.177 \\
IRI & 0.05 & 1.1 & 0.223 \\
HOMA-IR & 0.03 & 0.6 & 0.573 \\
Estradiol & 0.02 & 0.4 & 0.693 \\
Log hs-CRP & -0.03 & -0.6 & 0.552 \\
Systolic BP & -0.04 & -0.7 & 0.521 \\
Current smoker & -0.05 & -0.8 & 0.379 \\
\hline
\end{tabular}

$R^{2}=0.32, F$ value $=25.9, P<0.001, n=447 . r-A l x$ : radial augmentation index; T-T: total testosterone; d-ROMs: derivatives of reactive oxygen metabolites; CVD: cardiovascular disease; FBG: fasting blood glucose; IRI: immunoreactive insulin; HOMA-IR: homeostatic model assessment of insulin resistance; hs-CRP: high-sensitivity C-reactive protein; BP: blood pressure; $\beta$ : standardized regression coefficient; $R^{2}$ : coefficient of determination; $F$ value: variance ratio.

\section{Conclusion}

In conclusion, the results of this study indicated that low T-T is one of the important determining factors for increasing $r-$ AIx in Japanese postmenopausal patients. A prospective multicenter study with a large sample size is required to confirm the results of this study.

\section{Competing Interests}

Author has no competing interests.

\section{Grant Support}

None.

\section{Financial Disclosure}

None.

\section{References}

1. Laughlin GA, Barrett-Connor E, Bergstrom J. Low serum testosterone and mortality in older men. J Clin Endocrinol 
Metab. 2008;93(1):68-75.

2. Ziemens B, Wallaschofski H, Volzke H, Rettig R, Dorr M, Nauck M, Keevil BG, et al. Positive association between testosterone, blood pressure, and hypertension in women: longitudinal findings from the Study of Health in Pomerania. J Hypertens. 2013;31(6):1106-1113.

3. Patel SM, Ratcliffe SJ, Reilly MP, Weinstein R, Bhasin S, Blackman MR, Cauley JA, et al. Higher serum testosterone concentration in older women is associated with insulin resistance, metabolic syndrome, and cardiovascular disease. J Clin Endocrinol Metab. 2009;94(12):47764784.

4. Sievers C, Klotsche J, Pieper L, Schneider HJ, Marz W, Wittchen HU, Stalla GK, et al. Low testosterone levels predict all-cause mortality and cardiovascular events in women: a prospective cohort study in German primary care patients. Eur J Endocrinol. 2010;163(4):699-708.

5. Takazawa K, Kobayashi H, Shindo N, Tanaka N, Yamashina A. Relationship between radial and central arterial pulse wave and evaluation of central aortic pressure using the radial arterial pulse wave. Hypertens Res. 2007;30(3):219-228.

6. Williams B, Lacy PS, Thom SM, Cruickshank K, Stanton A, Collier D, Hughes AD, et al. Differential impact of blood pressure-lowering drugs on central aortic pressure and clinical outcomes: principal results of the Conduit Artery Function Evaluation (CAFE) study. Circulation. 2006;113(9):1213-1225.

7. Roman MJ, Devereux RB, Kizer JR, Lee ET, Galloway JM, Ali T, Umans JG, et al. Central pressure more strongly relates to vascular disease and outcome than does brachial pressure: the Strong Heart Study. Hypertension. 2007;50(1):197-203.

8. London GM, Blacher J, Pannier B, Guerin AP, Marchais SJ, Safar ME. Arterial wave reflections and survival in endstage renal failure. Hypertension. 2001;38(3):434-438.

9. Otsuka T, Kawada T, Ibuki C, Kusama Y. Radial arterial wave reflection is associated with the MEGA risk prediction score, an indicator of coronary heart disease risk, in middle-aged men with mild to moderate hypercholesterolemia. J Atheroscler Thromb. 2010;17(7):688-694.

10. Agarwal N, Rice SP, Bolusani H, Luzio SD, Dunseath G, Ludgate M, Rees DA. Metformin reduces arterial stiffness and improves endothelial function in young women with polycystic ovary syndrome: a randomized, placebo-controlled, crossover trial. J Clin Endocrinol Metab. 2010;95(2):722-730.

11. Weiss EP, Villareal DT, Ehsani AA, Fontana L, Holloszy JO. Dehydroepiandrosterone replacement therapy in older adults improves indices of arterial stiffness. Aging Cell. 2012;11(5):876-884.

12. Kohara K, Tabara Y, Oshiumi A, Miyawaki Y, Kobayashi T, Miki T. Radial augmentation index: a useful and easily obtainable parameter for vascular aging. Am J Hypertens. 2005;18(1 Pt 2):11S-14S.

13. Friedewald WT, Levy RI, Fredrickson DS. Estimation of the concentration of low-density lipoprotein cholesterol in plasma, without use of the preparative ultracentrifuge. Clin Chem. 1972;18(6):499-502.
14. Matthews DR, Hosker JP, Rudenski AS, Naylor BA, Treacher DF, Turner RC. Homeostasis model assessment: insulin resistance and beta-cell function from fasting plasma glucose and insulin concentrations in man. Diabetologia. 1985;28(7):412-419.

15. Cesarone MR, Belcaro G, Carratelli M, Cornelli U, De Sanctis MT, Incandela L, Barsotti A, et al. A simple test to monitor oxidative stress. Int Angiol. 1999;18(2):127-130.

16. Janner JH, Godtfredsen NS, Ladelund S, Vestbo J, Prescott E. High aortic augmentation index predicts mortality and cardiovascular events in men from a general population, but not in women. Eur J Prev Cardiol. 2013;20(6):10051012.

17. Higashi H, Okayama H, Saito M, Morioka H, Aono J, Yoshii T, Hiasa G, et al. Relationship between augmentation index and left ventricular diastolic function in healthy women and men. Am J Hypertens. 2013;26(11):12801286.

18. Yasmin, Brown MJ. Similarities and differences between augmentation index and pulse wave velocity in the assessment of arterial stiffness. QJM. 1999;92(10):595600.

19. Shargorodsky M, Boaz M, Luckish A, Matas Z, Gavish D, Mashavi M. Osteoprotegerin as an independent marker of subclinical atherosclerosis in osteoporotic postmenopausal women. Atherosclerosis. 2009;204(2):608-611.

20. Barbulescu AL, Vreju F, Cojocaru-Gofita IR, Musetescu AE, Ciurea PL. Impaired arterial stiffness in systemic lupus ertythematosus - correlations with inflammation markers. Curr Health Sci J. 2012;38(2):61-65.

21. Deenadayalu VP, White RE, Stallone JN, Gao X, Garcia AJ. Testosterone relaxes coronary arteries by opening the large-conductance, calcium-activated potassium channel. Am J Physiol Heart Circ Physiol. 2001;281(4):H17201727.

22. Hak AE, Witteman JC, de Jong FH, Geerlings MI, Hofman A, Pols HA. Low levels of endogenous androgens increase the risk of atherosclerosis in elderly men: the Rotterdam study. J Clin Endocrinol Metab. 2002;87(8):3632-3639.

23. Vlachopoulos C, Ioakeimidis N, Miner M, Aggelis A, Pietri P, Terentes-Printzios D, Tsekoura D, et al. Testosterone deficiency: a determinant of aortic stiffness in men. Atherosclerosis. 2014;233(1):278-283.

24. Akishita M, Hashimoto M, Ohike Y, Ogawa S, Iijima K, Eto M, Ouchi Y. Low testosterone level is an independent determinant of endothelial dysfunction in men. Hypertens Res. 2007;30(11):1029-1034.

25. Corrigan FE, 3rd, Al Mheid I, Eapen DJ, Hayek SS, Sher S, Martin GS, Quyyumi AA. Low testosterone in men predicts impaired arterial elasticity and microvascular function. Int J Cardiol. 2015;194:94-99.

26. Protogerou AD, Safar ME. Dissociation between central augmentation index and carotid-femoral pulse-wave velocity: when and why? Am J Hypertens. 2007;20(6):648649.

27. Soga J, Nakamura S, Nishioka K, Umemura T, Jitsuiki D, Hidaka T, Teragawa H, et al. Relationship between augmentation index and flow-mediated vasodilation in the brachial artery. Hypertens Res. 2008;31(7):1293-1298. 
28. Shiraki N, Nakashima A, Doi S, Carrero JJ, Sugiya N, Ueno T, Stenvinkel P, et al. Low serum testosterone is associated with atherosclerosis in postmenopausal women undergoing hemodialysis. Clin Exp Nephrol. 2014;18(3):499-506.

29. Worboys S, Kotsopoulos D, Teede H, McGrath B, Davis SR. Evidence that parenteral testosterone therapy may improve endothelium-dependent and -independent vasodilation in postmenopausal women already receiving estrogen. J Clin Endocrinol Metab. 2001;86(1):158-161.

30. Kondo T, Hirose M, Kageyama K. Roles of oxidative stress and redox regulation in atherosclerosis. J Atheroscler Thromb. 2009;16(5):532-538.

31. Manea A. NADPH oxidase-derived reactive oxygen species: involvement in vascular physiology and pathology. Cell Tissue Res. 2010;342(3):325-339.

32. Hitsumoto T. Clinical significance of the augmentation index in patients with preserved kidney function. $\mathrm{J}$ Nippon Med Sch. 2012;79(6):422-429.

33. Gomez-Marcos MA, Blazquez-Medela AM, Gamella-Pozuelo L, Recio-Rodriguez JI, Garcia-Ortiz L, Martinez-Salgado C. Serum superoxide dismutase is associated with vascular structure and function in hypertensive and diabetic patients. Oxid Med Cell Longev. 2016;2016:9124676.

34. Rovira-Llopis S, Banuls C, de Maranon AM, Diaz-Morales N, Jover A, Garzon S, Rocha M, et al. Low testosterone levels are related to oxidative stress, mitochondrial dysfunction and altered subclinical atherosclerotic mark- ers in type 2 diabetic male patients. Free Radic Biol Med. 2017;108:155-162.

35. Zhang L, Wu S, Ruan Y, Hong L, Xing X, Lai W. Testosterone suppresses oxidative stress via androgen receptorindependent pathway in murine cardiomyocytes. Mol Med Rep. 2011;4(6):1183-1188.

36. Noguera JC, Alonso-Alvarez C, Kim SY, Morales J, Velando A. Yolk testosterone reduces oxidative damages during postnatal development. Biol Lett. 2011;7(1):9395.

37. Beyazit F, Yilmaz N, Balci O, Adam M, Yaman ST. Evaluation of oxidative stress in women with polycystic ovarian syndrome as represented by serum ischemia modified albumin and its correlation with testosterone and insulin resistance. Intern Med. 2016;55(17):2359-2364.

38. Costa TJ, Ceravolo GS, dos Santos RA, de Oliveira MA, Araujo PX, Giaquinto LR, Tostes RC, et al. Association of testosterone with estrogen abolishes the beneficial effects of estrogen treatment by increasing ROS generation in aorta endothelial cells. Am J Physiol Heart Circ Physiol. 2015;308(7):H723-732.

39. Morakinyo AO, Adekunbi DA, Dada KA, Adegoke OA. Testosterone promotes glucose intolerance, lipid disorder and oxidative stress in type 1 diabetic rats. J Basic Clin Physiol Pharmacol. 2014;25(1):13-20.

40. Skogastierna C, Hotzen M, Rane A, Ekstrom L. A supraphysiological dose of testosterone induces nitric oxide production and oxidative stress. Eur J Prev Cardiol. 2014;21(8):1049-1054 